\title{
Building and using digital libraries in the developing world
}

\author{
Isaias Barreto da Rosa, David Ribeiro Lamas \\ Institute of Informatics, Tallinn University, Tallinn, Estonia
}

Email address:

ibr@tlu.ee(I. B. da Rosa),drl@tlu.ee (D. R. Lamas)

\section{To cite this article:}

Isaias Barreto da Rosa, David Ribeiro Lamas. Building and Using Digital Libraries in the Developing World. Education Journal. Vol. 2, No. 5, 2013, pp. 192-202. doi: 10.11648/j.edu.20130205.12

\begin{abstract}
Given the several problems faced by developing countries on their struggle to access print-based publications, digital libraries are seen as the great hope as they enable access to a vast panoply of resources, anytime and anywhere. However, building such libraries in developing countries is a real challenge since these countries usually face several difficulties, such as low computer and Internet penetration rates, poor ICT infrastructures, lack of qualified human resources, lack of financial resources, etc. Thus, it is imperative finding alternative mechanisms of building and accessing digital libraries that best fit the specificities of these countries. It is also important to understand how digital libraries are used in these contexts. This paper features the process used for building a digital library in a developing country, characterized by scarce access to print-based publications and serious difficulties in accessing ICT resources. The challenges, the solutions and the adopted methodological framework are highlighted and can be useful for other digital library projects in the developing world. The paper also presents a comparative study on the usage of the created digital library when compared with a traditional library with the same content, and introduces a user study on the possibility of using mobile phones for accessing digital libraries in this context.
\end{abstract}

Keywords: Digital Libraries, Developing Countries, Mobile Digital Libraries

\section{Introduction}

Developing countries have traditionally faced tremendous challenges on accessing print-based publications. In many places, making books, journals and similar materials available, is a real problem. Between 1998 and 2003, 56\% of the higher education institutions located in countries with less than US\$1000 GDP per capita, had no subscription to any international journal, and $21 \%$ had only 2 subscriptions[1]. In many of these countries, there are evidences that print-based library services have failed on their mission of providing relevant and timely information[2]. In fact, the traditional publishing and distribution mechanisms have tragically failed in developing countries [3].

Given the great difficulties on accessing print-based publications, the research results in these countries have low expression: among the 3.000 journals indexed by Medline in 2003 , only $2 \%$ were from developing countries and only $10 \%$ of the total research on health, are from these countries[4]. Between 1993 and 2001, 85\% of the most cited publications were from only 8 countries, led by the United
States of America, the United Kingdom, Germany and Japan, while 163 other countries (including mainly the developing ones), had only $2.5 \%$ of the total citations [5]. Moreover, print-based publications seem to be very expensive for the buying power of developing countries. In Africa, for instance, printed academic books cost too much for the majority of students in this continent [6]. In this context of asymmetric access to information, the scientific production of developing countries will keep having reduced impact [7].

Thus, digital libraries (DLs) seem to be the great hope for these countries by providing access to a great panoply of resources, theoretically anywhere and anytime, as far as, for instance, a computer with Internet access is available. In order to properly benefit from the potential of these libraries, it is necessary, however, to build digital libraries with local contents, so that people in these regions can access the national resources and publications. It is also necessary to have the indispensable devices and infrastructures for accessing these and other digital libraries.

Despite the great benefits of digital libraries for developing countries, they also face several problems on building and using such libraries. With the several basic 
problems they face, such as food, drinking water, sanitation, etc., spending the existing scarce resources on building these libraries is not a priority [3]. Apart from that, these countries face several other hindrances in this process [8]:

- Low training of human resources.

- Low digital and information literacy rates.

- Poor ICT infrastructure.

- Low Internet penetration rates.

- High costs of building digital libraries.

- Reduction of education budget.

- Lack of funding for libraries and research projects.

If building digital libraries in these contexts is a great challenge, there are several resources available online that can be accessed at a null cost, such as: open access journals and digital libraries, free electronic journals, free digital and virtual libraries, etc. Accessing these free resources require, though, that some basic ICT infrastructures are available for users. But people in the developing world can also use some other mechanisms to minimize this lack of basic ICT infrastructures: using refurbished computers, performing bandwidth optimization, making digital libraries available on local area networks, etc.

Despite these existing possibilities, it is still imperative finding additional alternative mechanisms that would facilitate building digital libraries in these countries, especially with local content, at a reduced cost, and that would enable people in this digital divide regions to have access to the existing DLs.

A good potential access mechanism is the usage of mobile phones. In 2012, in developing countries, while mobile phones penetration rate was $84.3 \%$, there were $27.6 \%$ households with a computer and 28 people using Internet for each 100 inhabitants [9]. On the other hand, in the developed world mobile phones penetration rate was $123.6 \%$, there were $75.5 \%$ households with a computer and 73 people using Internet for each 100 inhabitants. Therefore, with much more mobile phones than computers in the developing world, if digital libraries could be made properly accessible on mobile phones in these regions, they would reach a much broader range of people. In fact, in many developing countries, the majority of Internet users are mobile: out of the 10 top countries with regards mobile Web users who never or infrequently use the desktop Web, 9 are developing nation $^{1}$; In Kenya, for instance, $99 \%$ of Internet connections are mobile [10]. Between 2011 and 2013, the mobile broadband subscription in developing countries experienced a $240 \%$ increase [11]. There are currently companies such as Microsoft and Huawei producing smartphones especially tailored to the African market and simple budget smartphones can now be found in the streets of Kenya for US $\$ 50[12] \ldots$

In these circumstances, making digital libraries available on mobile devices can indeed contribute to ameliorate the accessibility of library materials at a global scale and, especially in the developing world where the access challenges are a major problem.

This paper presents and analyzes the process followed for building a digital library at the Jean Piaget University (UniPiaget), in Cape Verde, a developing country characterized by difficulties on accessing print-based publications, poor ICT infrastructures, low Internet penetration rates, shortage of financial resources, low level of digital literacy, etc. Since the challenges faced in this process are similar to the ones that might be faced in other developing countries, this paper presents the adopted solutions, along with the methodological approach that was followed. This paper also analyses how people from this digital divide context did use the created digital library as well as the possibility of accessing such library using mobile phones.

\section{Information Society and Digital Libraries in Cape Verde}

Cape Verde is a 10 islands archipelago with 491,875 inhabitants, $17.2 \%$ illiteracy rate $^{2}$ and a US\$3,946 GDP per capita. The country's GDP evolved from US\$300 in 1975 to US\$ 3,946 in $2013^{3}$. The Internet and mobile phone penetration rates have been experiencing important growths in the country, especially after the deregulation of the telecommunication sector in 2006/07. In 2006, the Internet penetration rate was around $5.2 \%$ and $23 \%$ of the Cape Verdean population had a mobile phone. In 2010/11, these rates had grown to $30 \%$ for Internet and $76 \%$ for mobile phones [13]. Therefore, in 5 years, there had been about 6 times increase on the Internet penetration rates and 3 times on the mobile phones' penetration rates. The country is ranked as number 6 in Africa, in terms of eGovernment index [14] and as number 4, on the Technology Development index[15].

Despite these figures, about $70 \%$ of the population does not have Internet access and only $11 \%$ of the Cape Verdean homes do have a computer. The country faces serious problems on accessing print-based publications, and there is no national network for book trade. Even accessing the national publications, especially the scientific ones, are often a real challenge. In this scenario, building and using digital libraries seem to be a good alternative. Most of the exiting traditional libraries (TLs) in the country look at the idea of building a digital library as something that they would embrace if resources were available. However, these libraries strongly depend on the external aid they receive: a survey conducted, among the existing traditional libraries in the country, revealed that $77 \%$ of them, do receive either donations of printed publications or external funding for 
acquiring such resources; $54 \%$ depend only on this aid, to acquire books and materials they have available; lack of qualified human resources is also one of the major problems they face.

Prior to the digital library of the Jean Piaget University of Cape Verde, there were no digital library initiatives in the whole country. Building such digital library in a context of shortage of financial resources, low Internet and computer penetration rates as well as difficulties on accessing print-based publication, has very specific challenges. The following sections describe the process that was followed for building this digital library.

\section{Building the Digital Library of the Jean Piaget University of Cape Verde}

The Jean Piaget University of Cape Verde was established on May $7^{\text {th }} 2001$, and was the first University created in the country. It currently has about 2,200 students and 200 lecturers for the 16 undergraduate courses it offers. UniPiaget is owned by Instituto Piaget, a Portuguese NGO.

Building a digital library at this University was a process that took place in different stages: in the beginning, in order to understand how the potential users would receive the idea of a digital library and if they would use it, a survey was conducted; then, their expectations were collected so that the digital library could better meet their needs; on the third stage, the requirements for the DL were defined, taking into consideration the users' inputs and the institutional policy; an open source DL system was selected according to the requirements that were defined and resources started being collected; the elected DL system was then installed, customized, populated and hosted in a proper location where bandwidth wouldn't be a major concern; the final stage was implementing a divulgation campaign among the potential users. Fig. 1 presents this process, which is analyzed in more detail in the subsequent subsections.

\subsection{User Acceptability}

The first step on the process of building the digital library of the Jean Piaget University of Cape Verde was a user study on the level of acceptance of the digital library by the potential users. Therefore, the main questions were: what is the level of acceptance of the digital library by the academic community of the University? Are the necessary requirements for using such library, in place? In order to get answers to these questions, a survey was conducted and out of the 1,300 students and 109 lecturers that existed at the University by the end of 2005, 184 people responded to the questionnaire. The survey tried to collect information mainly on four topics: computer and Internet access, ICT user skills, previous experience on using digital libraries and user preferences between printed and digital documents.

This study concluded that more than $50 \%$ of the members of the academic community of the University, did have computer and Internet access in at least one of three places: at home, at the University or at their working places, for those who were studying and working. The study also revealed that about $72 \%$ of these people had never used a digital library. Most had the basic computer user skills, since all the students had a computer user discipline in the first year at the University. About $37 \%$ of those who responded to the questionnaire preferred reading materials in print format but $35 \%$ would rather have these materials in digital format, with printing possibility.

The major conclusions of this initial survey were that in fact the conditions for using the digital library were indeed in place: people had access to computer and Internet and had the basic computer skills. It was also concluded that the future digital library should be well advertised and that the users should have the possibility of printing the materials that would be made available.

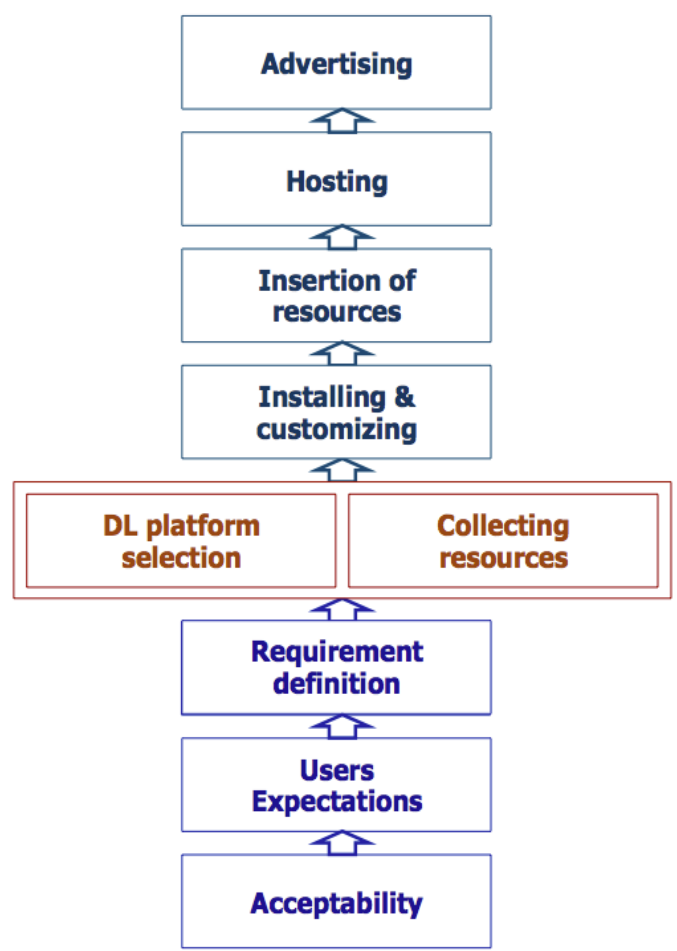

Figure 1.Phases on building the digital library

\subsection{Collecting Users Inputs}

After having a clear understanding that the digital library would have a good level of acceptance among the potential users, it was necessary to define what should be included in the digital library and what should be the functionalities of the system. In order to do this, and therefore to understand what were the expectations of the potential users, another survey was conducted among the academic community of the Jean Piaget University of Cape Verde. This survey took place during the second trimester of 2007 and comprised 331 people, among 1306 students and 178 lecturers that were at the University at that time. When assessing an existing digital library and/or when collecting users' inputs for building a new one, there are at least three aspects that should be taken into account [16]: 
- Data/collection - content description, quality and reliability, management and accessibility;

- Technology - information about user technology, document and information access technology as well as system structure technology.

- Users/uses - including information about the market, what they are interested in, their purposes and how they seek information.

The survey was elaborated taking these three aspects into consideration. Regarding to who the users were, this survey confirmed the information collected two years before: in general, they had regular computer access; they had no Internet access at home but they had it at the University or at their working places; they had no previous experiences on using digital libraries and they felt comfortable on using computers and Internet. This study brought some users' preferences on what could be the technological and data/collection specificities of the library, as presented in table 1 .

\subsection{Defining the Digital Library Requirements}

After understanding the level of acceptance of the digital library among the potential users and after collecting their inputs to build this library, it was necessary to choose the DL system that would be used. In this process, it was important to take into account that in each institution's case, the best DL software is the one that best aligns with the institution's specific requirements and needs [17]. Such requirements are guided by the institutional policy regarding to the content of the digital library and by several administrative and technical procedures that are necessary for implementing such policies. Thus, in order to choose the best digital library system for the project, it was necessary to define, beforehand, what were the requirements of this digital library, so that the chosen system would meet such requirements. In this process, users' inputs were very important since there were a clear understanding on the contents and functionalities they wanted for the library. For the purpose of choosing the digital library system, mainly the technical users' inputs were taken into consideration since they were the ones that would be more determinant on choosing the system.

Considering the Cape Verdean context of shortage of financial resources, the digital divide and the difficulties in accessing print-based library resources, the digital library had necessarily to require the minimum level of financial expenses. Therefore, taking into account the users' inputs and the University's objectives of bringing more resources close to the members of the institutions' academic community at the lowest possible cost, 14 requirements were defined for the digital library: Thus de DL system had to: (1) be free and open source; (2) have interface in Portuguese; (3) enable the creation of communities, sub-communities and collections; (4) have one page per collection and community, for better management; (5) enable interface customization; (6) allow both users and staff to submit materials; (7) enable metadata and content import and export; (8) be OAI-PMH complaint; (9) enable searching on selected metadata; (10) allow searching on the document body text; (11) allow browsing on selected metadata; (12) allow the available resources to be indexed by Web search engines (13) use, at least text, image and video materials; (14) include mechanisms for searching and for making news/information available.

Apart from these aspects, another important requirement of the digital library is related to the content. The idea was making available the scientific output of the University as well as other publications related to the Cape Verdean reality. Finding free digital libraries over the Internet is not a difficult task. However, there were no such digital libraries available, containing extensive resources about the Cape Verdean reality. Thus, the digital library of the Jean Piaget University of Cape Verde intended therefore to bring such resources and make them freely available according to the Open Access philosophy.

Table 1. User preferences

\begin{tabular}{ll}
\hline Characteristics & User preferences \\
\hline Functionality & Searching, collaboration and printing \\
Access & Searching on metadata, body text and browsing \\
File format & Essentially text, but also video and image \\
Reading & On screen with printing possibility \\
Main areas & Engineering/Technology, news and humanities \\
Resources & Thesis, dissertations, papers and teaching materials \\
Document size & Full documents \\
Document type & Both, peer reviewed and non peer reviewed \\
\hline
\end{tabular}

\subsection{Choosing the Digital Library Tools}

Given the requirements of the digital library, defined according to users' inputs and university's policy, a comparative analysis was made among 10 popular free open source digital library systems, in order to choose the one that would best meet these requirements. This comparative analysis was based on two techniques: on one hand, a literature review was carried out in order to collect information about the specificities and functionalities of each one of these tools, and on the other, they were installed and tested. Fig. 2 presents on the first column, the 10 digital library systems that were analyzed. On the remaining columns, there are the 14 ID numbers define in subsection 3.3 , corresponding to the 14 criteria that were used for comparing the DL systems. X1 means that the requirement is fully satisfied by the DL system, X2 means that the requirement is partially satisfied by the system and the empty space means that the requirement is not fulfilled by the DL system. 


\begin{tabular}{|l|c|c|c|c|c|c|c|c|c|c|c|c|c|c|}
\hline & $\mathbf{1}$ & $\mathbf{2}$ & $\mathbf{3}$ & $\mathbf{4}$ & $\mathbf{5}$ & $\mathbf{6}$ & $\mathbf{7}$ & $\mathbf{8}$ & $\mathbf{9}$ & $\mathbf{1 0}$ & $\mathbf{1 1}$ & $\mathbf{1 2}$ & $\mathbf{1 3}$ & $\mathbf{1 4}$ \\
\hline Archimede & $\mathrm{X} 1$ & & $\mathrm{X} 1$ & $\mathrm{X} 1$ & $\mathrm{X} 1$ & $\mathrm{X} 1$ & $\mathrm{X} 1$ & $\mathrm{X} 1$ & $\mathrm{X} 1$ & $\mathrm{X} 1$ & $\mathrm{X} 1$ & $\mathrm{X} 2$ & $\mathrm{X} 1$ & \\
ARNO & $\mathrm{X} 1$ & & & $\mathrm{X} 1$ & $\mathrm{X} 2$ & $\mathrm{X} 1$ & $\mathrm{X} 1$ & $\mathrm{X} 1$ & & & & & $\mathrm{X} 1$ & \\
CDS Invenio & $\mathrm{X} 1$ & $\mathrm{X} 1$ & $\mathrm{X} 1$ & $\mathrm{X} 1$ & $\mathrm{X} 1$ & $\mathrm{X} 1$ & $\mathrm{X} 1$ & $\mathrm{X} 1$ & $\mathrm{X} 1$ & $\mathrm{X} 1$ & $\mathrm{X} 1$ & $\mathrm{X} 2$ & $\mathrm{X} 1$ & $\mathrm{X} 2$ \\
DSpace & $\mathrm{X} 1$ & $\mathrm{X} 1$ & $\mathrm{X} 1$ & $\mathrm{X} 1$ & $\mathrm{X} 1$ & $\mathrm{X} 1$ & $\mathrm{X} 1$ & $\mathrm{X} 1$ & $\mathrm{X} 1$ & $\mathrm{X} 1$ & $\mathrm{X} 1$ & $\mathrm{X} 1$ & $\mathrm{X} 1$ & $\mathrm{X} 1$ \\
EPrints & $\mathrm{X} 1$ & $\mathrm{X} 1$ & & $\mathrm{X} 1$ & $\mathrm{X} 2$ & $\mathrm{X} 1$ & $\mathrm{X} 1$ & $\mathrm{X} 1$ & $\mathrm{X} 1$ & & $\mathrm{X} 1$ & $\mathrm{X} 2$ & $\mathrm{X} 1$ & \\
Fedora & $\mathrm{X} 1$ & $\mathrm{X} 1$ & & & $\mathrm{X} 1$ & & $\mathrm{X} 1$ & $\mathrm{X} 1$ & $\mathrm{X} 1$ & & $\mathrm{X} 1$ & $\mathrm{X} 2$ & $\mathrm{X} 1$ & \\
Greenstone & $\mathrm{X} 1$ & $\mathrm{X} 1$ & & $\mathrm{X} 1$ & $\mathrm{X} 2$ & & $\mathrm{X} 1$ & $\mathrm{X} 1$ & $\mathrm{X} 1$ & $\mathrm{X} 1$ & $\mathrm{X} 1$ & $\mathrm{X} 1$ & $\mathrm{X} 1$ & \\
i-Tor & $\mathrm{X} 1$ & & & $\mathrm{X} 1$ & $\mathrm{X} 1$ & $\mathrm{X} 1$ & $\mathrm{X} 1$ & $\mathrm{X} 1$ & $\mathrm{X} 1$ & $\mathrm{X} 1$ & $\mathrm{X} 1$ & $\mathrm{X} 1$ & $\mathrm{X} 1$ & \\
MyCoRe & $\mathrm{X} 1$ & & & & $\mathrm{X} 1$ & & $\mathrm{X} 1$ & $\mathrm{X} 1$ & $\mathrm{X} 1$ & $\mathrm{X} 1$ & $\mathrm{X} 1$ & $\mathrm{X} 2$ & $\mathrm{X} 1$ & \\
OPUS & $\mathrm{X} 1$ & & & $\mathrm{X} 1$ & $\mathrm{X} 1$ & $\mathrm{X} 1$ & $\mathrm{X} 2$ & $\mathrm{X} 1$ & $\mathrm{X} 1$ & $\mathrm{X} 1$ & $\mathrm{X} 2$ & $\mathrm{X} 1$ & $\mathrm{X} 1$ & \\
\hline
\end{tabular}

Figure 2. DL systems vs. technical requirements

From this comparative analysis, the conclusion was that DSpace was the best alternative for building the digital library of the Jean Piaget University of Cape Verde, since it was the only one that met all the requirements of the project. The second system that positively responded to most of the requirements was CDS. However, this system could not accept the insertion of news and the indexation process by the Web search engines was complicated. This does not mean however, that DSpace is the best alternative for all digital library projects. As previously mentioned, the best DL system is the one that best suits the organizational needs.

\subsection{Collecting Bibliographic Resources}

In order to collect resources for the digital library, the users' inputs on what they wanted to be included in the library was an important element that was taken into consideration. As presented in table 1, thesis and dissertations as well as articles, were the main users' preferences. They also wanted to have access to the full documents. Thus, after collecting these users' inputs, contact was established with the management of the University so that all thesis and dissertations could start being submitted to the University in digital format, along with the hard copies. This was necessary to avoid eventual digitization costs, since digitization is one of the most expensive part in the process of building any digital library[18]. With the acceptance of this proposal, an important and cost effective source of materials was found.

An agreement was also reached with Contacto, the University journal, so that all the articles published in this journal could also be made available in the digital library. Apart from that, all the lecturers of the University were contacted and asked to contribute to the digital library, making their resources available according to the Open Access philosophy.

\subsection{Setting up, Customizing and Inserting Resources}

After choosing the digital library system, DSpace was installed and customized. Communities and collections were created and the available materials were made available on the system. The different communities and collections were assigned to the different academic organizational units (departments) that had responsibilities over the corresponding scientific field. All the inserted resources would then have to be reviewed and approved by the digital library team in order to ensure the proper metadata validation and respect to the copyright laws.

\subsection{Hosting}

An important challenge on building digital libraries in Cape Verde and in many other developing countries is related to the Web hosting services. In order to do that locally, it is necessary to have an Internet connection available with proper bandwidth and static routable IP address so that the domain name can be registered. However, in Cape Verde the prices of such Internet connection lines are currently very expensive and were even more so in 2008, when the digital library was about to be made available. These costs are particularly expensive, when compared to the price policy that existed in developed countries such as Portugal for instance (that is culturally and historically closer to Cape Verde), at the same date. Some key aspects could be highlighted out of these comparisons:

- The speed of the Internet connection lines was much lower in Cape Verde. The ADSL lines had a $1 \mathrm{Mbps}$ maximum downstream speed, while in Portugal, a 12 Mbps connection was available.

- All the ADSL connection lines that existed in Cape Verde had a limited monthly downstream quota and users would have to pay an additional fee for additional traffic, after having reached this monthly limit.

- All the ADSL lines in the country had a dynamic IP address, while in Portugal there were flat rate services available, with static IP addresses.

- In Cape Verde, the best available ADSL line (in terms of speed) had a 1 Mbps downstream bandwidth, dynamic IP address and 1GB monthly traffic limit. The monthly price was 363.64 Euros. In Portugal, the best ADSL that was then available had $12 \mathrm{Mbps}$ bandwidth, had a flat rate cost of 29.90 Euros and included a static routable IP address.

For a proper hosting of digital library services over an ADSL line, it was necessary a proper bandwidth with static 
and routable IP address as well as an affordable price. Such line was not available in the country. The alternative was the usage of a leased line connection, which included a static IP address and had a better quality of service than ADSL lines. However, the prices were prohibitive: for example, for a 512 Kbps connection line, 5,090.91 Euros had to be paid.

Thus, it was very difficult to host the digital library services in Cape Verde. Actually, in 2008, 68\% of the Web sites under ".cv" domain name were hosted outside the country. Out of the $36 \%$ that were in Cape Verde, $78 \%$ were hosted at NOSI[19], the public institution that is responsible for the management of all the government ICT infrastructure and that had a special price reduction agreement with the major existing ISP in the country. Under these circumstances, it was necessary to find a more affordable hosting service for the digital library. After analyzing several possibilities, three major alternatives came up:

1. Choosing an external hosting service.

2. Hosting the digital library at the University, but using a dynamic DNS service.

3. Hosting the digital library on the servers of Instituto Piaget in Portugal.

At first, the usage of an external hosting service seemed to be the best alternative. The University Web site was using this service as well as most of the".cv" Web sites. After analyzing this possibility, the conclusion was that, in fact, it was very difficult, since DSpace requires some additional components (Apache Tomcat, Java, etc.) that the regular Web hosting services did not offer. Even the ones that would make exclusive servers available had serious constraints regarding these indispensible DSpace requirements. Thus, the special DSpace hosting services were analyzed. They were technically very good, but the costs were also very high for the context of shortage of financial resources that characterizes Cape Verde. In some cases, the annual fees for a special DSpace hosting service would reach US\$12,500.

With these expensive costs (for the context of developing countries) of external hosting services for DSpace, another alternative mechanism started being considered to make the digital library available: hosting the DL at the Jean Piaget University of Cape Verde but using an ADSL line (128 $\mathrm{Kbps} / 1,024 \mathrm{Kbps}$ ) with dynamic IP address, which would not enable a regular registration of the domain name. Thus, a dynamic IP address DNS registration service had also to be considered. In this case, whenever the IP address is dynamically changed, the DNS server is automatically updated with the new IP address. For this approach to really work, there are two main possibilities: (1) a dynamic DNS complaint ADSL router is used, to automatically update the DNS server whenever the address is changed; (2) a specific software is installed, for instance on the same machine where DSpace is hosted, and this software automatically updates the DNS server whenever the IP address is changed. These dynamic DNS services are usually free but some payment might be needed when additional functionalities are required. For the purpose of hosting the digital library of the Jean Piaget University of Cape Verde, the free services would be enough, and no payment would have to be made.

There are, however, two major drawbacks on the usage of this service: (1) the domain name is usually a sub-domain of the domain that is made available by the provider. For instance, it is not possible to have a "bdigital.org" domain name, but rather "bdigital.selfip.org"; (2) after updating the IP address on the DNS server, it might take some time before such change can reach other DNS servers over the Internet. This fact might cause the Web site to be unavailable for a certain period of time. Another aspect that has to be taken into account when using this hosting mechanism is that in ADSL lines the downstream bandwidth is lower than the upstream bandwidth. This means that when a $128 \times 1,024$ ADSL line is used $(128 \mathrm{Kbps}$ upstream and 1,024 downstream) at the server side, in fact, the final user will always have a $128 \mathrm{Kbps}$ maximum bandwidth.

Given the challenges in finding an affordable and reliable hosting service for the digital library, contacts were established with Instituto Piaget (the owner of the Jean Piaget University of Cape Verde), in order to host the library on the servers of this institution in Portugal. The initial contact was made in December 2007, but in August 2008 the server was not yet available. Thus, the dynamic DNS service was used and the digital library was hosted at the University. A few weeks later though, a server was made available in Portugal and the digital library was hosted in this country at null cost for the Jean Piaget University of Cape Verde and with a very good bandwidth.

\subsection{Advertising}

After having the digital library available, it was necessary to perform the proper advertising. In fact a proper advertising of a digital library is a fundamental requisite for success. Reference [20] indicates that the lack of knowledge (and therefore a poor advertisement), is the main reason for the reduced usage rate of online books. Reference [21] also shows that a good advertisement and promotion strategy is indeed critical for the success of an institutional repository. This divulgation should not be confined to the potential users, but, especially in the case of open access digital libraries, it should also include authors, and researchers, so that they can accept making their publications available on the DL. In this process, it is important to promote specific sessions to present the library and to clarify eventual copyright and other issues. For the case of the Jean Piaget University of Cape Verde, several advertisement actions were implemented: emails to the lecturers of the University presenting the project and requesting collaboration on making their publications available according to the open access philosophy; advertisement over the e-learning platform of the University; posters at the University informing the members of the academic community about the availability of the digital library; links were inserted into several reference sites, such as the University Web site, etc. 


\section{Usage of Digital VS. Traditional Library}

Since this was the first digital library ever built in Cape Verde, and taking into consideration the country's problems with regard to accessing scholarly publications as well as ICT resources, it was important to understand how people would use such digital library in this context. Thus, a study was conducted to analyze the usage of this DL and to perceive how it was being used when compared to a traditional library with the same content.

Different approaches have been used to study the usage of digital libraries. To understand the users and the usage of digital libraries in France, Assadiand Beauvisage[22] resorted to three different data collecting mechanisms: online survey (to understand the users' profile), Internet traffic analysis and interviews. In his studies on the usage of the digital music libraries at Indiana University, Notess [23] used a different approach, with three techniques: questionnaire to understand the level of user satisfaction regarding the digital library, session activity log analysis, and contextual inquiry. Users' activities for each session were analyzed according to the system logs. Using tools that were developed specifically for this purpose Notess [23] could analyze the activities performed by the user in the library. The contextual inquiry, as explained by the author, is a technique that combines observation and interview methods to interpret the work practices, i.e., the researcher observes people working (using the digital library, in this case), takes notes and asks questions. To study the usage of the Computer Science Technical Reports Collection of the New Zealand Digital Library, transaction log analysis was used[24]. These logs were automatically processed in order to extract specific statistics and summaries, as requested by the researchers.

Therefore, several techniques have been used to study the usage of digital libraries, and some of the most popular are[25]: questionnaire, log analysis, interview, observation, usability testing, focus group and diary study. But to perform a good usage study, it is critical to resort to distinct mechanisms for collecting data[26]. Thus, in order to study how the UniPiaget digital library was being used, several mechanisms were utilized: (1) DSpace logs analysis, to provide some DL usage statistics: number of accesses, number of downloads, etc.; (2) Google Analytics, to provide several additional information such as: access per regions, how often the same user returns to the DL, etc. (3) online survey, to collect information on the users characteristics and on the context on which they were using the DL.

The metrics used for analyzing the usage of traditional libraries have been addressed by many researchers but there are three who are of real prominence on this topic[27]: James Gerould, F. Wilfrid Lancaster and Duane Webster. The concept of digital library is not the same as the concept of traditional library and there are metrics used specifically to evaluate the usage of traditional libraries [28]. However, users' objectives and evaluation criteria are basically the same in these two types of libraries[29]. Thus, there are several metrics used for evaluating traditional libraries which are also relevant for evaluating digital libraries [26]: the library usage (number of visits, number of visits vs. target public, etc.), usage of materials (how many times a certain item was used) and access to materials (number of searches). Therefore, there are some correspondences between the parameters used for evaluating these libraries. For example, the number of visits to the TL could be equivalent to the number of visits to the DL web site; the access to materials and the ratio of use in the TL could be equivalent to the number of documents viewed or printed on the DL[28]...

In order to understand how the UniPiaget traditional library was used, Bibliobase (the library system used at the University library) logs were analyzed. These logs store information on the usage of resources at the library, including: which materials were used, who used them, when they were used, etc. All the materials that were available in the DL were also available in the TL, but not all resources available in the TL were available in the DL. Thus, the comparative analysis involved only the materials that were available in the two libraries.

\subsection{Results}

The study on the usage of the digital and traditional libraries of the Jean Piaget University took place right after the library was made available online and during 142 days, between August $11^{\text {th }}$ and December $31^{\text {st }}$ 2008. The comparative analysis between the usage of the two libraries were made according to the above mentioned parameters established by [26], [28] and [29]. The key results of this comparison are presented in the following subsections.

\subsubsection{Access and Usage}

The DL was accessed 2,951 times by 2,050 users and each one of them spent $4 \mathrm{mn} 45 \mathrm{secs}$ on the website (table 2). By its turn, the TL had 1,912 users, but only 43 of them $(2.2 \%)$ spent some time visiting the library; they visited the collections for 89 times. Therefore the DL was accessed 33 times more than the traditional library and the number of users was 48 times higher. Fig. 3 shows the evolution on the number of visits to the two libraries during the study and highlights the big gap between them.

There were 6,083 accesses to the DL resources (about 43 accesses per day); 2,279 searches were made and each item was accessed 38 times (table 2). In the traditional library, there were 89 accesses to the available resources ( 0.6 access per day); 41 materials were viewed out of 161 available ( $25 \%$ of the materials were used). Thus, the resources in the DL were accessed 68 times more than in the traditional library. 
Table 2. Usage of digital vs. traditional library: some indicators

\begin{tabular}{lll}
\hline Indicator & $\begin{array}{l}\text { Digital } \\
\text { Library }\end{array}$ & $\begin{array}{l}\text { Traditional } \\
\text { Library }\end{array}$ \\
\hline Total items that were viewed & 89 & 6083 \\
Number of accessed items & 41 & 161 \\
Percentage of accessed items & $25 \%$ & $100 \%$ \\
Average daily item access & 0.6 & 42.8 \\
Average item access per user & 2.1 & 3.0 \\
Average access per item & 2.1 & 37.8 \\
Total users & 43 & 2050 \\
Average new user per day & 0.3 & 14.4 \\
\hline
\end{tabular}

The Google Analytics statistics showed that out of the 2,050 digital library visitors, 65.4\% were accessing from Cape Verde. These people spent about 6 minutes in the DL and $43.1 \%$ of them did return to the DL website. The remaining $34.6 \%$ of the visitors were from 37 other countries, they spent an average of 2 minutes on the DL and $15 \%$ of them did return (the DL interface and materials were in Portuguese). Therefore, the DL library definitely brought more visibility to the resources that were made available but the most users were indeed from Cape Verde.

\subsubsection{Users}

Bibliobase $\operatorname{logs}$ showed that all the TL users were either students or lecturers of the University. Therefore, given these logs, it was quite straightforward to identify and analyze who these users were. However, studying the usage of digital libraries through log analysis encloses two major drawbacks[25]: they neither reveal information about who the users are nor do they show the context under which the digital libraries are used. Thus, in order to overcome these weaknesses, an online survey was conducted to collect additional information about the users of the DL and the context in which they were using it. This survey was made available online on the digital library's home page and 97 users (3.3\% of the total DL users) decided to take it. Among the conclusions of this survey there were at least two, which were particularly relevant to understand who these users were and the context under which they were using the library: (1) more than $90 \%$ of the respondents were members of the academic community of the Jean Piaget University of Cape Verde; (2) users were mainly students who were accessing the DL from a university context (78\%). Therefore, the users and the usage context of the digital and traditional libraries had many similitudes: users were mainly members of the academic community of the Jean Piaget University of Cape Verde, who were using the two libraries in university context. However, many users did access the DL from outside the UniPiaget's physical setting and from outside the country as showed by the Google Analytics statistics.

These numbers indicate that in fact, despite the context of shortage of financial resources and difficulties in accessing ICT resources, materials were much more used in the digital library than in the traditional library. While users from 38 countries could access the digital library $(2,050$ in total), the traditional library was used only by members of the academic community of UniPiaget (41 students and 2 lecturers). This better visibility was not only outside the country but also at domestic level: $65.4 \%$ of those who accessed the DL did it from Cape Verde. On the other hand, $95 \%$ of those who responded to the online survey were members of the academic community of the Jean Piaget University of Cape Verde.

This study shows, therefore, that in countries like Cape Verde, characterized by shortage of financial resources, lack of print-based publications and difficulties in accessing ICT resources, DLs could substantially contribute to an increase in the visibility and usage of library materials, both inside and outside the country. The same resources available in digital libraries can be used more by local users then when they are available in traditional libraries.

\section{Accessing the Digital Library on Mobile Phones}

Considering that, as mentioned above, in developing countries such as Cape Verde, there are many more people using mobile phones than computers and that in many developing nations there are many more people using Internet on their mobile phones than on computers, making digital libraries properly accessible on mobile devices can improve the accessibility of library materials in these nations.

However, accessing digital libraries on mobile phones is different than accessing such libraries using regular desktop computers and encloses important specificities and challenges: the small size of the screen which negatively affects the users' effectiveness in completing tasks [30] and requires adjusting the contents to a small display area [31], the usage environment which is very prone to distractions, etc. Taking into account these specificities of mobile access to digital libraries, there have been some initiatives on making digital libraries available on mobile devices and some traditional libraries have been making part of their services available on mobile phones[32]. In the process of enabling mobile access to services available on the Internet, either through mobile web or through native applications, it is critical to know the users beforehand, to understand what their needs are, which devices they use, etc.[33].

\subsection{User Study on a Potential Mobile Digital Library}

Given the potential of mobile digital libraries in the developing nations, a project was conceived, to enable mobile access to DSpace-based digital libraries and therefore to enable mobile access to the digital library of Jean Piaget University of Cape Verde. An initial study was conducted to collect user requirements, to know which mobile phone they use and to understand if they would use digital libraries on their mobile devices. 


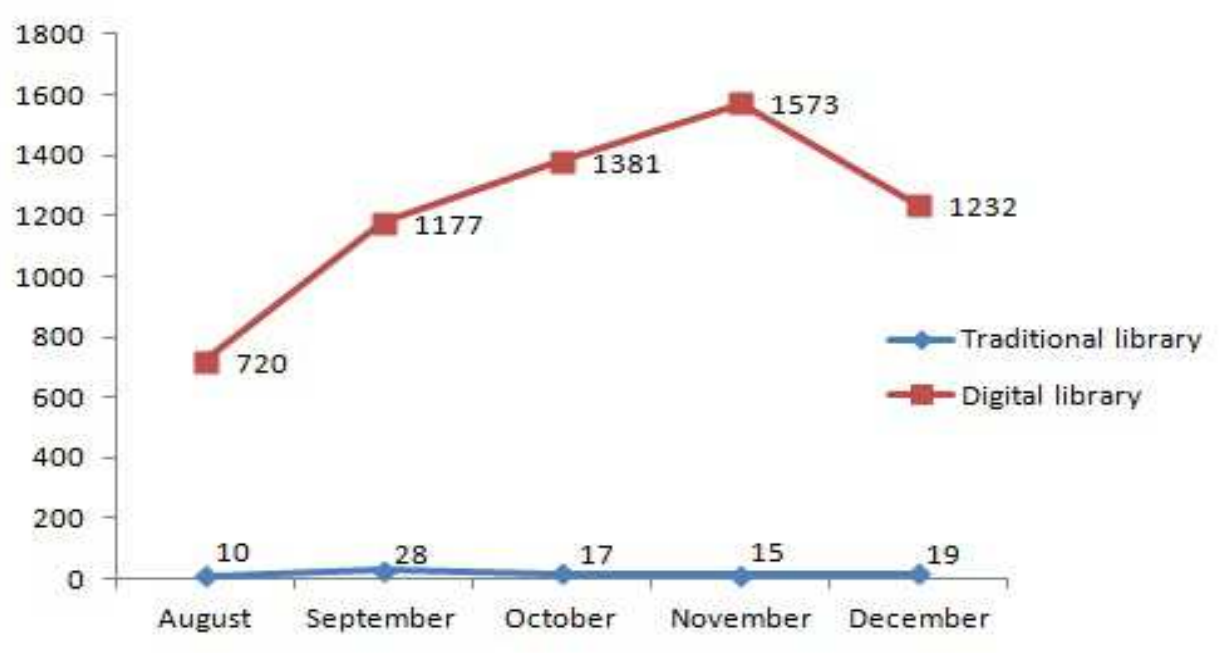

Figure 3. Evolution on the access to the two libraries

The survey took place between January $24^{\text {th }}$ and February $2^{\text {nd }} 2012$, and involved 312 potential users among the 2,100 students and 200 lecturers, which the University had at that time. People from all areas responded to the questionnaire that was divided into four main parts: (1) ICT access; (2) usage of mobile devices; (3) accessing online academic materials; (4) expectations. The survey results are presented and analyzed bellow.

\subsubsection{ICT Access}

The survey revealed a level of ICT access far above the Cape Verdean average: $86.5 \%$ of those who responded to the survey had a computer at home, and laptop was owned by $71 \%$. Therefore, approximately $15 \%$, had both, a desktop and a laptop computer at home! Apart from that, $11 \%$ intend to acquire a laptop within the next 6 months! Regarding the Internet access, $69.7 \%$ revealed that they had an easy Internet access, while in the entire country, the Internet penetration rate was around $30 \%$ !

Thus, despite the low level of computer and Internet penetration rates in the country, the members of the University's academic community revealed that in general, they did have access to such ICT resources.

\subsubsection{Usage of Mobile Devices}

According to the survey, mobile phones were owned by $97.4 \%$ of the students and lecturers of the University and $16 \%$ of them, owned iPhones. If we consider iPhones and other modern devices (namely iPod Touch, iPad, Blackberry, Android, and Windows Mobile), this percentage raises up to $43 \%$. Moreover, $26 \%$ of the respondents had plans to acquire one of these devices within the following 6 months.

Therefore, after 6 months about $69 \%$ of the potential users at the University would have a smartphone, iPod Touch or tablet, that could be used for accessing an eventual DSpace-based digital library.

However, only $29 \%$ of the potential users had subscription to Internet access services on mobile phones. Those who did not have such subscription explained that the main reasons for not doing so were the low quality of service, high costs, and the fact that they didn't really need it. Even those who had subscribed the service explained that they usually don't use it when an Internet connected computer is available.

\subsubsection{Accessing Online Academic Materials}

Only $22 \%$ of the potential users of the mobile digital library had the habit of reading academic materials online, using their mobile devices. Approximately the same percentage of users would download these materials using their mobile devices, for further offline readings.

From a user's perspective, the major barriers against the usage of mobile phones for accessing academic materials were: WiFi/mobile network unavailability $(39.4 \%)$, speed (35.9\%), application unavailability $(27.2 \%)$ and small screen size $(21.7 \%)$.

\subsubsection{Expectations}

When inquired if they would use digital libraries on their mobile phones, $73.7 \%$ responded positively. There are mainly three functionalities they would like to see available on a mobile phone accessible digital library: content downloading $(59 \%)$, reading materials online $(56 \%)$ and searching (49\%).

After conducting this survey, the key findings can be summarized as follows:

- Users did have computer, Internet and mobile phone access. iPhone was the most popular smartphone among them.

- Most users did not own a smartphone, but in 6 months' time, about $69 \%$ of them would acquire a smartphone, an iPod or a tablet.

- Most users did not have the habit of reading academic materials on their mobile phones due mainly to unavailability of $\mathrm{WiFi} / \mathrm{mobile}$ network, slow 
connection speed, application unavailability and small screen size.

- Users would use a digital library available over mobile devices and would like to have the possibility of reading the contents offline.

\section{Conclusion}

Digital libraries seem to be the hope for developing countries on their struggle to access scientific and academic publications. However, building and using such libraries in these countries are a serious challenge, due to several problems developing countries face in this process. Building a digital library at the Jean Piaget University of Cape Verde, and therefore in a developing country, characterized by shortage of financial resources, poor ICT infrastructures, low Internet penetration rates, etc., required finding alternative solutions for problems that other similar projects might find. Some key points learned from this case, are:

- In a developing country context, where bandwidth is scarce and expensive it is important to find alternative ways of hosting digital libraries for the sake of a better bandwidth and lower costs. An external hosting service should be considered whenever it is affordable. However, partnerships with other institutions from places where bandwidth is not as big an issue as it is in developing countries might be a good alternative.

- For making a digital library freely available according to the Open Access philosophy, it is very important to sensitize academics and authors so that they can make their publications available on the digital library.

- When building a digital library in a developing country context, the usage of open source software is imperative. When choosing the proper open source software, it is necessary to, firstly, define the requirements of the digital library taking into consideration the users needs and expectations. The requirements of the digital library should be the key player in choosing the open source digital library system to be used.

- Collecting users' inputs and understanding their expectations seem to be an important requirement for building a digital library that meets their needs.

- An effective advertisement mechanism should be used so that the digital library can have a proper level of usage among the target audience.

This paper has shown that digital libraries built in these countries can strongly contribute to ameliorate the visibility of the available materials both inside and outside the country. When in these contexts, the same resources are available in both, digital and traditional libraries, they tend to be used more in the digital libraries despite the existing challenges. This paper has also shown that the usage of mobile devices for accessing digital libraries in the developing world is a good alternative for improving the accessibility of library materials in these countries and people seem to be willing to use such alternative access mechanism.

\section{References}

[1] B. Aronson, "Improving Online Access to Medical Information for Low-Income Countries," New England Journal of Medicine, vol. 350, no. 10, pp. 966-968, 2004.

[2] J. M. Kavulya, "Digital libraries and development in Sub-Saharan Africa: A review of challenges and strategies.," The Electronic Library, vol. 25, no. 3, pp. 299-315, 2007.

[3] I. H. Witten, M. Loots, M. F. Trujillo, and D. Bainbridge, "The promise of digital libraries in developing countries," Communications of the ACM, vol. 44, no. 5, pp. 82-85, 2001.

[4] R. Smith, "Publishing research from developing countries," Statistics in Medicine, vol. 19, no. 21, pp. 2869-2877, 2002.

[5] D. King, "The scientific impact of nations. What different countries get for their research spending.," Nature, vol. 430, no. 21, pp. 311-316, 2004.

[6] P. Ngimwa, "An African experience in providing a digital library service: the African Virtual University example," 4 th Pan Commonwealth Forum on open learning . 2006.

[7] L. Chan and S. Costa, "Participation in the global knowledge commons: Challenges and opportunities for research dissemination in developing countries," New Library World, vol. 106, no. 1210-1, pp. 141-163, 2005.

[8] G. Chowdhury, "Digital Divide: How Can Digital Libraries Bridge the Gap?," in Proceedings of the 5th International Conference on Asian Digital Libraries: Digital Libraries: People, Knowledge, and Technology, 2002, vol. 58, no. 3, pp. 258-283.

[9] ITU, "ICT Facts and Figures," Geneva, Switzerland, 2013.

[10] CCK, "Mobile subscribers in the country inch towards 30million," Communications Comission of Kenya, 2012. [Online].

Available: http://www.cck.go.ke/news/2012/Mobile_Subscribers.html. [Accessed: 09-Aug-2013].

[11] ITU, "Key ICT indicators for developed and developing countries and the world," International Telecommunication Union, 2013. [Online]. Available: http://www.itu.int/en/ITU-D/Statistics/Pages/stat/default.asp x. [Accessed: 09-Aug-2013].

[12] M. Labrooy, “Africa's smartphone revolution," eLearnin Africa, 2013. [Online]. Available: http://www.elearning-africa.com/eLA_Newsportal/africas-s martphone-revolution/. [Accessed: 08-Aug-2013].

[13] ANAC, "Compêndio das estatísticas dos mercados de serviços públicos das comunicações electrónicas em Cabo Verde 2010.” Agência Nacional de Comunicações, Praia, 2010 .

[14] United Nations, "E-Government Survey 2010. Leveraging e-government at a time of financial and economic crisis." UN - Department of Economic and Social Affairs, New York, 2010 .

[15] ITU, Measuring the Information Society. Geneva: International Telecommunication Union, 2011.

[16] N. Fuhr, P. Hansen, M. Mabe, A. Micsiky, and I. Solvbergz, "Digital Libraries: A Generic Classification and Evaluation 
Scheme," in Proceedings European Conference on Digital Libraries, 2001, pp. 187-199.

[17] R. Crow, "A guide to institutional repository software,” 2004.

[18] I. H. Witten and D. M. Nichols, How to Build a Digital Library, Second Edition. Boston: Morgan Kaufmann, 2010.

[19] A. Fernandes, “Tecnologias Livres de Desenvolvimento Web Desenvolvimento Web em Cabo Verde," Universidade Jean Piaget de Cabo Verde, Praia, 2008.

[20] J. F. B. Rowland, C. McKnight, and A. J. Meadows, Project ELVYN, an experiment in electronic journal delivery: facts, figures, and findings. Bowker-Saur, 1995.

[21] E. Rodrigues, M. Almeida, Â. Miranda, A. Guimarães, and D. Castro, "RepositóriUM: criação e desenvolvimento do Repositório Institucional da Universidade do Minho," in Congresso Nacional de Bibliotecários, Arquivistas e Documentalistas, 2004.

[22] H. Assadi, T. Beauvisage, C. Lupovici, and T. Cloarec, "Users and Uses of Online Digital Libraries in France," Proceedings of the 7th European Conference on Research and Advanced Technology for Digital Libraries ECDL. Springer, pp. 1-12, 2003.

[23] M. Notess, "Three looks at users: a comparison of methods for studying digital library use," Information Research, vol. 9, no. 3,2004

[24] S. Jones, S. J. Cunningham, R. Mcnab, and S. Boddie, "A transaction log analysis of a digital library," International Journal on Digital Libraries, vol. 3, pp. 152-169, 2000.

[25] N. Bryan-Kinns and A. Blandford, "A Survey of User Studies for Digital Libraries. Working Paper.” 2000.
[26] L. Neumann and A. Bishop, "From usability to use: measuring success of testbeds in the real world," in in Successes and failures of digital libraries, M. Harum S., Twidale, Ed. Urbana-Champaign, IL: University of Illinois., 2000 , pp. 58-69.

[27] M. Kyrillidou and C. Cook, "The evolution of measurement and evaluation of libraries: a perspective from the Association of Research Libraries," Library Trends, vol. 56, no. 4,2008

[28] A. P. Bishop, "Measuring Access, Use, and Success in Digital Libraries ," The Journal of Electronic Publishing, vol. 4, no. 2,1998

[29] F. W. Lancaster, "Are Evaluation Criteria Applied to 'Traditional' Libraries Equally Applicable to Digital Libraries?," How We Do User-Centered Design and Evaluation of Digital Libraries: A Methodological Forum, 37th - Allerton Park Institute Proceedings, no. 37. 1995.

[30] G. Marsden, N. Mohd-Nasir, K. Boone, and G. Buchanan, "Improving Web Interaction on Small Displays," Computer Networks, vol. 31, no. 11-16, pp. 1129-1137, 1999.

[31] F. C. Choy, "Digital library services: towards mobile learning," Seminar on E-books as Learning Resources in Chinese Libraries in Asia. National Kaohsiung University of Applied Science, Kaohsiung, Taiwan, 2010.

[32] C. Mitchell and D. Suchy, "Developing Mobile Access to Digital Collections," D-Lib Magazine, vol. 18, no. 1/2, 2012.

[33] R. Budiu and J. Nielsen, "Usability of Mobile Websites and Applications - Design Guidelines for Improving the User Experience of Mobile Sites and Apps." Nielsen Norman Group, Fremont, 2011. 